\title{
Macrometric and Micrometric Study of Sexual Dimorphism in Foramina of Middle Crania Fossa of Adult Nigerians
}

\author{
Estudio Macrométrico y Micrométrico del Dimorfismo Sexual \\ en Foramina de la Fosa Craneal Media en Nigerianos Adultos
}

\author{
C. N. Orish \& B. C. Didia
}

ORISH, C. N \& DIDIA, B. C. Macrometric and micrometric study of sexual dimorphism in foramina of middle crania fossa of adult Nigerians. Int. J. Morphol., 28(2):519-524, 2010.

SUMMARY: We have measured the longitudinal, transverse diameters of optic canal, foramen rotundum, foramen ovale, foramen spinosum, to serve as a handy guideline to surgeons, to enhance the accuracy of sexing the cranium for anthropometric/medico-legal studies and for comparative analyses of values of the Nigerian population with those of the Caucasians. A total of 100 adult dry skulls 81 male, 19 female from departments of Anatomy of some Nigerian Universities were used. Automatic vernier caliper with a precision of $0.1 \mathrm{~mm}$ was used. Data analysis was performed with Graph Pad Prism 3.0. A comparison was made of the means of the dimension using Student's T-test and analysis of variance. Sizes of foramina were not significantly different from that of Caucasians Our results show significant sexual dimorphism in the following parameters, the right transverse diameter of the FR in males was found to be significantly different from the females at $\mathrm{p}<0.05$, there was a significant difference between the means of the left and right sides of the foramen ovale. The distance between right ovale and spinosum in males and females was found to be significantly different in both sexes. The effect of side on longitudinal diameter of foramen ovale FO of males showed a significant difference between the means of the left and right sides of the foramen ovale. A comparism of the distance between left optical canal and foramen rotundum showed a significant difference between the values obtained for males and the females at $\mathrm{p}<0.05$.

KEY WORDS: Macrometric study; Micrometric study; Sexual dimorphism; Foramina; Middle crania fossa.

\section{INTRODUCTION}

To identify the deceased person from bones is the most common and critical problem faced by anatomist, forensic science experts and anthropologist. Skeletal remains have been used for sexing the individual as bones of the body are last to perish after death, next to enamel of teeth. Almost all bones of the human skeleton show some degree of sexual dimorphism. Sex of the deceased can be determined if cranium is available for study. Earlier traditional studies by non-metrical methods were centered on morphological traits which were not reliable because more features depends on occupation, nutrition, race, geographical regions and visual impressions change from person to person.

Subsequently trends changed to morphometry and statistical methods like univariate analysis, demarcating point and use of indices. In these methods many parameters show overlap between male and female value so the bones cannot be sexed correctly with $100 \%$ accuracy. The recent trend is to apply advanced analytical methods to metrical data. Armitage (1971) described such important method, multivariate linear discriminant functional analysis, so sexing can be done with almost 100\% accuracy. Hanihara (1959) worked on Japanese skull, Giles \& Elliot (1963) worked on American crania and Song et al. (1992) studied Chinese skull by using multivariate linear discriminant functional analysis.

As studies on sexual dimorphism of cranium were very few especially in the Nigerian population we have taken this study to enhance the accuracy of sexing the cranium which will be helpful in anthropometric and medico legal studies. 


\section{MATERIAL AND METHOD}

Methodology. A total of 100 adult dry skulls 81 male, 19 female from departments of Anatomy in Nigerian Universities constituted the materials for this study.

Automatic vernier caliper with a precision of $0.1 \mathrm{~mm}$ was used to measure the following parameters:

-Left transverse and longitudinal diameters of optic canal. -Right transverse and longitudinal diameters of optic canal. -Left transverse and longitudinal diameter of foramen rotundum. -Right transverse and longitudinal diameter of foramen rotundum. -Left transverse and longitudinal diameter of foramen ovale. -Right transverse and longitudinal diameter of foramen ovale -Left transverse and longitudinal diameter of foramen spinosum. - Right transverse and longitudinal diameter of foramen spinosum.

Attempt was made to sex the cranium using the following parameter the skull of an adult female is as a rule a little lighter and smaller, and its capacity is about 10 percent less than that of the male. Its walls are thinner and its muscular ridges less marked; the glabella, superciliary arches, and mastoid processes are less prominent,, and the corresponding air sinueses are smaller. The tympanic part of the temporal bone is smaller and its margin of the orbit is sharp, the forehead vertical, the frontal and parietal tuberosities are prominent, and the vault somewhat flattened. The contour of the face is rounder, the facial bones are smoother, and the mandible and maxillae and their contained teeth smaller.

Also each skull was examined for shapes of foramen rotundum, optic canal, foramen ovale and spinosum along with the bony growth (if present) around the margins of the foramina in the form of spines turbercles bridges (bony spurs) and bony plates on both sides.

Data analysis was performed with Graph Pad Prism 3.0. The mean, standard deviation, standard error of mean and ranges of each parameter were computed. Right and left differences were analized. A comparison was made of the means of the dimension using Student's T-test and analysis of variance.

\section{RESULTS}

Table I shows diameters of foramina and canal of adult dry skulls, male and female Nigerians.

The mean difference in all the measured diameters of optical canal between the two sexes were not statistically significant at $p>0.05$. The difference between the right and the left longitudinal diameters of the optic canal in males was not statistically significant. The difference between the right and the left transverse diameters of optic canal in females was not statistically significant at $\mathrm{p}>0.05$.

The difference in means of the left, right longitudinal and left transverse diameters of foramen rotundum in males and females were not statistically significant at $p>0.05$. The effect of side (left or right) on longitudinal diameter of foramen rotundum FR of males, and on transverse diameter of foramen rotundum FR of females were not significant at $\mathrm{p}>0.05$

There was no significant difference between the means of the left and right sides of the foramen ovale (longitudinal and transverse in both sexes). There was no significant difference between the means of the left and right sides of the foramen ovale in females.

The mean difference in all the measured diameters of foramen spinosum between the two sexes were not statistically significant at $\mathrm{p}>0.05$. The difference between the right and the left longitudinal diameters of the foramen spinosum in males was not statistically significant. The difference between the right and the left transverse diameters of foramen spinosum in females was not statistically significant at $\mathrm{p}>0.05$.

Table II shows the distance between different foramina in male and female Nigerians.

Taken together our results show significant sexual dimorphism in the following parameters, the right transverse diameter of the FR in males was found to be significantly different from the females at $\mathrm{p}<0.05$, there was a significant difference between the means of the left and right sides of the foramen ovale. The distance between right ovale and spinosum in males and females was found to be significantly different in both sexes.

The effect of side on longitudinal diameter of foramen ovale FO of males showed a significant difference between the means of the left and right sides of the foramen ovale.

A comparison of the distance between left optical canal and foramen rotundum showed a significant difference between the values obtained for males and the females at $\mathrm{p}<$ 0.05 .

Most of the foramina were oval and circular in shape without tubercles. 
Table I. Diameters (mm) of foramina and canal in male and female Nigerians.

\begin{tabular}{lllll}
\hline Foramina & \multicolumn{2}{c}{ Male } & \multicolumn{2}{c}{ Female } \\
\hline Left longitudinal diameter of optic canal OC & $4.12 \pm 0.09$ & $(2.5-6.0)$ & $4.06 \pm 0.14$ & $(3.2-5.8)$ \\
Right longitudinal diameter of optic canal OC & $4.13 \pm 0.09$ & $(3.0-6.0)$ & $4.06 \pm 0.78$ & $(3.0-5.5)$ \\
Left transverse diameter of optic canal OC & $4.04 \pm 0.40$ & $(3.0-7.0)$ & $4.32 \pm 0.20$ & $(3.05-5.8)$ \\
Right transverse diameter of optic canal OC & $4.21 \pm 0.11$ & $(3.0-7.0)$ & $4.12 \pm 0.18$ & $(2.8-5.50)$ \\
Left longitudinal diameter of foramen rotundum FR & $3.39 \pm 0.10$ & $(2.0-5.0)$ & $3.57 \pm 0.16$ & $(2.5-4.5)$ \\
Right longitudinal diameter of foramen rotundum FR & $3.40 \pm 0.07$ & $(2.0-4.8)$ & $3.77 \pm 0.18$ & $(2.5-5.5)$ \\
Left transverse diameter of foramen rotundum FR & $3.23 \pm 0.09$ & $(2.0-5.2)$ & $3.63 \pm 0.15$ & $(2.5-4.5)$ \\
Right transverse diameter of foramen rotundum FR & $3.24 \pm 0.07$ & $(2.0-4.8)$ & $3.63 \pm 0.13 *(2.5-4.5)$ \\
Left longitudinal diameter of foramen ovale FO & $7.37 \pm 0.09$ & $(5.63-8.85)$ & $7.28 \pm 0.23$ & $(5.63-9.13)$ \\
Right longitudinal diameter of foramen ovale FO & $8.10 \pm 0.14$ & $(6.25-10.3)$ & $8.42 \pm 0.40$ & $(6.08-12)$ \\
Left transverse diameter of foramen ovale FO & $4.11 \pm 0.82$ & $(2.0-5.2)$ & $4.10 \pm 0.14$ & $(2.82-4.76)$ \\
Right transverse diameter of foramen ovale FO & $4.09 \pm 0.10$ & $(2.0-7.0)$ & $3.87 \pm 0.25$ & $(2.63-7.00)$ \\
Left longitudinal diameter of foramen spinosum FS & $2.82 \pm 0.05$ & $(1.78-3.92)$ & $2.93 \pm 0.14$ & $(2.08-4.25)$ \\
Right longitudinal diameter of foramen spinosum FS & $2.71 \pm 0.08$ & $(1.06-5.06)$ & $2.77 \pm 0.10$ & $(2.02-3.52)$ \\
Left transverse diameter of foramen spinosum FS & $2.38 \pm 0.04$ & $(1.18-3.04)$ & $2.26 \pm 0.47$ & $(1.78-2.48)$ \\
Right transverse diameter of foramen spinosum FS & $2.45 \pm 0.06$ & $(1.06-3.70)$ & $2.31 \pm 0.10$ & $(1.89-3.11)$ \\
\hline
\end{tabular}

* $\mathrm{p}<0.05$ significant difference, values in parenthesis show ranges.

Table II. Distance $(\mathrm{mm})$ between different foramina in male and female Nigerians.

\begin{tabular}{lrlll}
\hline Distance between: & \multicolumn{1}{l}{ Male } & \multicolumn{2}{c}{ Female } \\
\hline Right ovale and spinosum & $2.54 \pm 0.13$ & $(1.00-6.16)$ & $1.80 \pm 0.20^{*}(1.00-2.87)$ \\
Left ovale and spinosum & $2.71 \pm 0.11$ & $(1.18-5.00)$ & $3.36 \pm 0.33^{*}$ & $(1.54-6.4)$ \\
Right optical canal and foramen rotundum & $14.63 \pm 0.25$ & $(11.00-19.00)$ & $14.09 \pm 0.36$ & $(11.00-17.00)$ \\
Left optical canal and foramen rotundum & $14.51 \pm 0.23$ & $(10.9-19.00)$ & $13.02 \pm 0.29^{*}(11.00-14.7)$ \\
\hline
\end{tabular}

$* \mathrm{p}<0.05$ significant difference, values in parenthesis show ranges.

\section{DISCUSSION}

Identification on skeletal and decomposing human remains is one of the most difficult skills in forensic medicine. Sex determination is also an important problem in the identification. If almost all the bones composing the skeleton are present, sex estimation is not difficult. When the skeleton exists completely, sex can be determined with $100 \%$ accuracy. However, in explosions, warfare and, other mass disasters like aircraft crashes, identification and sex determination are not very easy. Every well-trained forensic pathologist or examiner knows the importance of the morphological indicators such as mastoid process, orbit and glabella, but when these parts of the skull are fragmented, morphological evaluation is not always easy. In addition, there are few forensic examiners who are well-trained in formal anthropology in many countries including Nigeria, and there are no experienced anthropologists and crime laboratories which are nearby and easily accessed.
Anthropologists have suggested that the morphometric method based on measurement is as useful as the morphological method based on observation (Longia, 1990). It is particularly sensitive when the sex determination method is based on discriminant function analysis. In previous studies, it has been reported that the measurements of cranium, long bones, clavicle and sternum in both sexes are different (Güleç \& Is scan, 1994; Bennet, 1987). There are also several specific studies into the mandibular dimensions, sternum and ribs Cologlu (1998), which are based on osteometric criteria. Some studies have drawn attention to the fact that the size of the some foramen is larger in the males in comparison to females (Fatteh, 1973; Teixeria, 1982; Günay \& Altinkök, 2000). These studies were done with fewer samples of skulls and it was suggested that the study was to be expanded to a larger sample for which a more complete statistical analysis would be given. Günay 
\& Altinkök, study confirmed that the area of foramen magnum is larger in males than in females. Despite this result, one area of foramen magnum alone is never sufficient to determine sex. It may be as useful an adjunctive method in the absence of evidence.

In view of these observations and even more cited in the aims and objectives, the present study has employed more than one cranial parameter for sex determination in adult Nigerians with an attempt to ascertain whether there are racial differences too between these cranial indices.

In a study of the optic foramen by Goalwin (1927a, 1927b), the diameter was measured as $4.1-4.65 \mathrm{~mm}$ on longitudinal roentgenograms. Direct measurements by Lindblom (1936) vary between 4 X $4 \mathrm{~mm}$ and 5 X $5 \mathrm{~mm}$, and he postulated that "one is entitled to consider values over $5 \mathrm{X}$ $5 \mathrm{~mm}$ and a difference between the two sides of larger than $20 \%$ to be at least suspiciously pathological." Our study showed that the right side optical canal in adult male Nigerians had $4.13 \times 4.21$ and $4.06 \times 4.12 \mathrm{~mm}$ in females. While the left dimensions for both male and female Nigerians were $4.12 \mathrm{x}$ 4.04 and $4.06 \times 4.32 \mathrm{~mm}$ respectively.

In a study carried out in China on 200 skulls, the transverse diameter of the optic canal was $3.57 \pm 0.61 \mathrm{~mm}$, the longitudinal diameter was $4.82 \pm 0.38$. It showed no significant difference between the two sides of the optic canal diameters (p>0.5) (Liu et al., 2000).

In the Berge \& Bergman (2001) study of the variations in Size and in Symmetry of foramina of the human skull, the average height and width for the foramen rotundum of $2.66 \mathrm{x}$ $33.26 \mathrm{~mm}$ corresponds well with a study of 20 dry skulls by Sondheimer (1971), which showed an average height of 2.9 (range, $2-4 \mathrm{~mm}$ ) and average width of 3.2 (range, $1.5-4$ $\mathrm{mm}$ ). In the present study the dimensions for the right side of the foramen rotundum in adult male Nigerians were $3.40 \mathrm{x}$ $3.24 \mathrm{~mm}$. The female have the following dimensions $3.77 \mathrm{x}$ $3.63 \mathrm{~mm}$. The dimensions on the left side for males were 3.39 x 3.23 and females had $3.57 \times 3.63 \mathrm{~mm}$.

In males and females of adult Nigerians we found the dimensions of right foramen ovale to be as follows 8.10 x $4.09,8.42 \times 3.87 \mathrm{~mm}$ respectively. The left sided dimensions were $7.37 \times 4.11$ and $7.28 \times 4.10 \mathrm{~mm}$ in males and females respectively. Our results agree with the data compiled by Radoievitch et al. (1956), who found the average size to be 3-4 x 4-8 mm with a range of 1 - 6 × 5 - 10 $\mathrm{mm}$. Lang (1983) reported $7.26 \times 3.65$; maximum, $9.9 \times$ 9.7; minimum, $4.2 \times 1.7$. The foramen ovale is very variable in size as noted by its wide range. The major factors in the determination of variability of size and shape of the fora- men ovale are thought to be the presence and number of veins that pass through it (Henderson, 1966).

When present, the accessory meningeal branch of the internal maxillary artery enters the skull through the posterolateral portion of the foramen ovale. This artery supplies trigeminal ganglion and a portion of the dura. Occasionally, there may be a separate foramen for the artery on the lateral aspect of the foramen ovale.

Furthermore, Chinese Doctors (2006) who conducted a study on diameter and form of foramen ovale with three dimensional spiral CT scan using 50 healthy adult skulls, reported that the longitudinal diameters of left and right foramen ovales were $(7.67 \pm 1.32)$ and $(7.98 \pm 1.45)$ respectively, and the transverse diameter of left and right were (4.04 \pm 0.83$)$ and(4.09 \pm 1.07$)$ respectively. There was no obvious difference between left and right longitudinal diameters, and left and right transverse diameters were close.

Lindblom measured the short axis of the foramen spinosum, which averaged $2 \mathrm{~mm}(1.5-3 \mathrm{~mm})$ with an average difference in the long and short axis to be $0.5 \mathrm{~mm}$. The dimensions of the right side of the foramen spinosum in adult male and female Nigerians were 2.71 x 2.45, 2.77 x $2.31 \mathrm{~mm}$ respectively. The left sided dimensions were $2.82 \times 2.38$ and $2.93 \times 2.26 \mathrm{~mm}$ in males and females respectively.

Anatomical observations have shown that the ovale foramen is highly asymmetrical, with the left side invariably large than the right side. In contrast, the rotundum foramen is only slightly asymmetrical, but is larger on the left than on the right side in $75 \%$ of the cases. Radiological findings have also shown that frequently the rotundum and ovale foramens on the left side are significantly wider than those on the right (Lang, 1991, Berge \& Bergmann 2001, Keskil et al., 2003).

Taken together our results show significant sexual dimorphism in the following parameters, the right transverse diameter of the FR in males was found to be significantly different from the females at $p<0.05$, there was a significant difference between the means of the left and right sides of the foramen ovale. The distance between right ovale and spinosum in males and females was found to be significantly different in both sexes.

The effect of side on longitudinal diameter of foramen ovale FO of males showed a significant difference between the means of the left and right sides of the foramen ovale.

A comparism of the distance between left optical canal and foramen rotundum showed a significant difference between the values obtained for males and the females at $\mathrm{p}<0.05$. 
ORISH, C. N. \& DIDIA, B. C. Estudio macrométrico y micrométrico del dimorfismo sexual en foramina de la fosa craneal media en Nigerianos adultos. Int. J. Morphol., 28(2):519-524, 2010.

RESUMEN: Hemos medido el diámetro longitudinal y transversal del canal óptico, agujero redondo, el agujero oval, agujero espinoso, para que sirva como una guía útil para los cirujanos, para mejorar la exactitud de la determinación del sexo del cráneo para estudios antropométricos y médico-legales y para realizar análisis comparativos de valores de la población de Nigeria con los de la raza blanca. Fueron utilizados 100 cráneos adultos secos 81 cráneos masculinos, 19 femeninos de los departamentos de Anatomía de algunas Universidades de Nigeri. Se utilizó un calibrador vernier automático con una precisión de $0,1 \mathrm{~mm}$. Los datos fueron analizados con el gráfico Pad Prism 3.0. Se realizó una comparación de los medios de la dimensión utilizando T de Student y el análisis de la varianza. Los tamaños de los agujeros no fueron significativamente diferentes de la de los caucásicos. Nuestros resultados muestran dimorfismo sexual significativo en los siguientes parámetros, el diámetro transversal del derecho de FR en los hombres resultó ser significativamente diferentes de las hembras con una $\mathrm{p}<0,05$, hubo una diferencia significativa entre las medias de los lados izquierdo y derecho del foramen oval. La distancia entre la derecha y oval espinoso en hombres y mujeres resultó ser significativamente diferente en ambos sexos. El efecto de lado en el diámetro longitudinal del foramen oval DE de los hombres mostraron una diferencia significativa entre las medias de los lados izquierdo y derecho del foramen oval. Una comparación de la distancia entre el canal izquierdo y agujero redondo óptica mostró una diferencia significativa entre los valores obtenidos para los machos y las hembras de $\mathrm{p}<0,05$.

PALABRAS CLAVE: Estudio macrométrico; Estudio micrométrico; Dimorfismo sexual; Foramina; Fosa cranial media.

\section{REFERENCES}

Armitage, P. Statistical methods in medical research. Oxford, Blackwell, 1971.

Bennet, K. A. A field guide for human skeletal identification. Springfield Illinois, Charles C. Thomas Pub, 1987. pp.14-6.

Berge, J. K. \& Bergman, R. A. Variations in size and in symmetry of foramina of the human skull. Clin. Anat., 14(6):406-13, 2001.

Fatteh, A. Handbook of Forensic Pathology. Philadelphia, J.B. Lippincott Company, 1973. pp.51-9.

Giles, E. \& Elliot, G. Sex determination by discriminant function analysis of crania. Am. J. Phys. Anthropol., 21:53-68, 1963.

Goalwin, H. A. One thousand optic canals. A clinical, anatomic and roentgenologic study. JAMA, 89(21): 17458, 1927a.

Goalwin, H. A. The profile roentgenogram of the optic canal. Am. J. Roentgenol., 17:573-9, 1927b.

Güleç, E. S. \& Is scan, M. Y. Forensic anthropology in Turkey. Forensic Sci. Int., 66:61-8, 1994.

Günay, Y. \& Altinkök, M. The value of the size of foramen magnum in sex determination. J. Clin. Forensic Med., 7:147-9, 2000.
Hanihara, K. Sex diagnosis of Japanese skulls and scapulae by means of discriminant function. J. Anth. Soc. Nippon, 67(722):21-7, 1959.

Henderson, W. R. A note on the relationship of the human maxillary nerve to the cavernous sinus and to an emissary sinus passing through the foramen ovale. J. Anat., 100:905-8, 1966.

Keskil, S.; Gözil, R. \& Calgüner, E. Common surgical pitfalls in the skull. Surg. Neurol., 59:228-31, 2003.

Lang, J. Clinical anatomy of the head. Neurocranium, Orbit, Craniocervical regions. Berlin, New York, Springer Verlag, 1983.

Lang, J. Clinical anatomy of the posterior cranial fossa and its foramina. New York, Thieme, 1991. pp.1-12.

Lindblom, K. A roentgenographic study of the vascular channels of the skull. Acta. Radiol., 30:211-23 1936.

Liu, X.; Zhou, C.; Zhang, G.; Lin, Y. \& Li, S. CT anatomic measurement of the optic canal and its clinical significance. Zhonghua Er. Bi. Yan Hou Ke Za Zhi, 35(4):275-7, 2000.

Longia, G. S. Anthropometrical features laryngeal cartilages. Adli. Tip. Dergisi., 6:141-8, 1990.

Radoievitch, S.; Jovanovitch, S. \& Lotritch, N. La 
ORISH, C. N \& DIDIA, B. C. Macrometric and micrometric study of sexual dimorphism in foramina of middle crania fossa of adult Nigerians. Int. J. Morphol., 28(2):519-524, 2010.

morphologie du trou ovale et les rapports du nerf maxilaire inferieur avec le sinus sphenoidal. Rev. Laryngol. Otol. Rhinol., 77:11-9, 1956.

Sondheimer, F.K. In: Radiology the skull and brain:basal foramina and canals. Newton, T. H. \& Potts, D. G. (editors). St. Louis, Mosby, 1971. pp.287-308.

Song, H. W.; Lin, Z. Q. \& Jia, J. T. Sex diagnosis of Chinese skulls using multiple stepwise discriminant function analysis. Forensic Sci. Int., 54(2):135-40, 1992.

Teixeria W. R. G. Sex identification utilizing the size of the foramen magnum. Am. J. Forensic. Med. Pathol., 3:2036, 1982.
Correspondence to:

Orish Chinna N.

Dept of Anatomy, Faculty of Basic Medical Sciences College of Health Sciences, University of Port Harcourt Choba, Port Harcourt

Rivers State

NIGERIA.

E-mail: chinnaorish@yahoo.com

Received: 10-09-2009

Accepted: 04-11-2009 